\title{
A Comprehensive Evaluation of the Construction of Innovation Cities in Xuzhou City Based on Principal Component Analysis Rong xiaohong
} Institute of information management, Xuzhou College of IndustrialTechnology, Xuzhou, 221140, China.

rxh823@126.com

Keywords: innovative city; evaluation index; principal component analysis;

\begin{abstract}
The evaluation of innovation cities assesses the realization level of innovative cities through the evaluation of the comprehensive innovative level. In this paper, the author builds an innovative city competitiveness evaluation index system based on the theoretical analysis, and evaluates Xuzhou city and other 12 prefecture-level cities the innovation capacity through principal component analysis. Alterations made recommendations based on the evaluation results, in order to provide the ability to provide innovative Xuzhou basis for decision making.
\end{abstract}

\section{Introduction}

In the 21st century, innovation has become the first driver of a country or region's economic development. Thus "innovative city" has become the focus of academic at home and abroad. Chard Florida $^{[1]}$ has done the city innovation ability evaluation of the United States from the empirical aspects, he adopts the index mainly includes high-tech, innovative, and human resources. EIS ${ }^{[2]}$ thought that an core indicators of innovative city innovation ability included technology, talent and tolerance, which thus created the innovation capability index evaluation method.In the domestic, from the subjective and objective view, Fengxia ${ }^{[3]}$ gives a new urban construction process of evaluation index should at least include ideas, the level of science and technology, system, macro environment and cultural atmosphere and so on five categories of innovation index. Song Hefa ${ }^{[4]}$ gives the evaluation index system of the national innovation city, including the innovation foundation, the accumulation of innovation resources, the innovation efficiency and the benefit, innovation and the ability of the innovation and the radiation.

The purpose of this article is to build an innovative city competitiveness evaluation index system based on the theoretical analysis, and evaluate Xuzhou city and other 12 prefecture-level cities the innovation capacity through principle analysis method. Thus it promotes the rapid development of Xuzhou innovative urban construction.

\section{Evaluation Process}

\subsection{Construction of Evaluation Index System.}

According to the theory of an innovative urban construction, the paper eventually builds a set of evaluation system from the subject of theinnovative city construction, content, environment and internal mechanism. The author selected 5 level indicators and 15 second-level indicators. Finally the author established the index system of innovative city competitiveness evaluation. Such as table 1. 
Tab.1 Innovative city competitiveness evaluation index system

\begin{tabular}{|c|c|c|}
\hline Level indicator & Second-level indicators & ers \\
\hline \multirow{3}{*}{$\begin{array}{l}\text { Innovation } \\
\text { research } \\
\text { ability -Y1 }\end{array}$} & $\mathrm{R} \& \mathrm{D}$ full-time equivalent & $\mathrm{X}_{1}$ \\
\hline & \multicolumn{2}{|l|}{ Patent application authorization quantity $\mathrm{X}_{2}$} \\
\hline & $\begin{array}{c}\text { Per million population activities of science and } \\
\text { technology personnel }\end{array}$ & $\mathrm{X}_{3}$ \\
\hline \multirow{3}{*}{$\begin{array}{l}\text { Innovation } \\
\text { environment -Y2 }\end{array}$} & Fixed assets investment in the city & $\mathrm{X}_{4}$ \\
\hline & Per capita consumption of urban residents & $\mathrm{X}_{5}$ \\
\hline & Ordinary middle school number & $\mathrm{X}_{6}$ \\
\hline \multirow{3}{*}{$\begin{array}{l}\text { Innovation } \\
\text { output } \\
\text { ability-Y3 }\end{array}$} & $\begin{array}{l}\text { high and new technology industrial enterprises output } \\
\text { value }\end{array}$ & $\mathrm{X}_{7}$ \\
\hline & $\begin{array}{l}\text { high and new technology industrial enterprises output } \\
\text { value as a share of Regional output value }\end{array}$ & $\mathrm{X}_{8}$ \\
\hline & High and new technology product output & $\mathrm{X}_{9}$ \\
\hline \multirow{3}{*}{$\begin{array}{c}\text { Innovation } \\
\text { Benefit } \\
\text { Ability-Y4 } \\
\end{array}$} & GDP per capita & $\mathrm{X}_{10}$ \\
\hline & Urban per capita disposable income & $\mathrm{X}_{11}$ \\
\hline & Registered urban unemployment rate & $\mathrm{X}_{12}$ \\
\hline \multirow{3}{*}{$\begin{array}{l}\text { Innovation } \\
\text { investment } \\
\text { ability-Y5 }\end{array}$} & Large and medium-sized industrial enterprise R\&D funds & $\mathrm{X}_{13}$ \\
\hline & $\mathrm{R} \& \mathrm{D}$ spending as a share of $\mathrm{GDPX}_{14}$ & \\
\hline & Government spending & $X_{15}$ \\
\hline
\end{tabular}

\subsection{Collection and Standardization}

The main data of this paper comes from statistical yearbook, such as Jiangsu statistical yearbook 2013, Jiangsu science and technology yearbook 2013. The data standardization processing mainly includes two aspects: data assimilation and non- dimensional treatment.Data assimilation is mainly to solve the problem of different nature data, and change the nature of the inverse index data, so that all the indexes of the evaluation scheme are the same as the force of the method. Data non dimensional treatment is to solve the comparability of data. So we use the exponential processing method. The concrete formula is as follows:

$$
\mathrm{z}_{\mathrm{i}}=\left(\mathrm{x}_{\mathrm{i}}-\mathrm{X}_{\min }\right) /\left(\mathrm{x}_{\max }-\mathrm{x}_{\min }\right)
$$

Where $Z_{i}$ represents Standard scores, and the $x_{\max }$ and $x_{\min }$ represent the maximum and the minimum of the index in the all cities, respectively.

\subsection{Factors Analysis}

After standardizing the raw data, the no-dimensional data were inputted SPSS14.0 software. The Principal Components Analysis with a varimax rotation was used with a predetermined cut-off Eigenvalue of one. Three factors were found with Eigenvalues $\geq 1$, and they accounted for $93.178 \%$ of the total variance.

Then, the Rotated Component Matrix was followed. Its first principal components include $\mathrm{X}_{2}$, $\mathrm{X}_{9}, \mathrm{X}_{7}, \mathrm{X}_{5}$ four indexes, the second factors contain $\mathrm{X}_{14}, \mathrm{X}_{8}, \mathrm{X}_{3}, \mathrm{X}_{11}, \mathrm{X}_{10}$, and the third factors have high loading in the $\mathrm{X}_{1}, \mathrm{X}_{6}$.

\subsection{Factors Scores}

The factor score coefficients were obtained with the regression algorithm and shown in the factor score matrix. The total variance contribution rate of each factor was weighted and then the total factor scores of the cities were obtained. The total factor score function as follow:

$\mathrm{F} 1 \times 37.329 / 93.178+\mathrm{F} 2 \times 36.439 / 93.178+\mathrm{F} 3 \times 19.410 / 93.718$

After calculation, each city factor scores in Jiangsu Province were obtained.The factor score, 
comprehensive score and rank of each county are shown in Table 2.

Tab.2The Innovation capacity evaluation composite scoreand ranking of Xuzhou in

2012

\begin{tabular}{ccllllccc}
\hline \multirow{2}{*}{ City } & \multicolumn{7}{c}{ Component } \\
\cline { 2 - 9 } & F1 & rank & F2 & rank & F3 & rank & comprehensive score & rank \\
\hline Xuzhou & .01087 & 4 & -.78171 & 11 & .31516 & 2 & -0.23608 & 8 \\
Nanjing & -.46242 & 10 & .74187 & 4 & 3.15309 & 1 & 0.75808 & 2 \\
Wuxi & .67689 & 2 & 1.21705 & 2 & -.27643 & 6 & 0.68961 & 3 \\
Changzho & -.38282 & 8 & 1.19253 & 3 & -.58308 & 12 & 0.19238 & 4 \\
Suzhou & 3.02157 & 1 & .18522 & 6 & -.01831 & 5 & 1.27798 & 1 \\
Nantong & .26079 & 3 & .05894 & 7 & -.30273 & 7 & 0.06473 & 5 \\
Lianyunga &.- .45984 & 9 & -.74678 & 10 & -.37871 & 8 & -0.55452 & 11 \\
Huaian & -.53158 & 11 & -.73136 & 9 & -.46783 & 10 & -0.59566 & 12 \\
Yancheng & -.13206 & 6 & -1.04753 & 12 & .05433 & 4 & -0.45126 & 10 \\
Yangzhou & -.57688 & 12 & .43871 & 5 & -.39602 & 9 & -0.14134 & 7 \\
Zhenjiang & -1.01782 & 13 & 1.37948 & 1 & -.74287 & 13 & -0.02175 & 6 \\
Taizhou & -.30459 & 7 & -.00589 & 8 & -.57378 & 11 & -0.24305 & 9 \\
Suqian & -.10212 & 5 & -1.90055 & 13 & .21717 & 3 & -0.73914 & 13 \\
\hline
\end{tabular}

\section{Conclusions}

\subsection{The analysis of comprehensive score}

As shown in Table 2,Xuzhou city in the ranking of the innovation ability of the city areas of Jiangsu province ranked eighth, indicating that Xuzhou city innovation ability is still in an early stage. In addition, the city innovation ability and Patent application authorization quantity and GDP per capita in Jiangsu Province are positively correlated. The highest comprehensive scores are got by Suzhou, followed by Nanjing, Wuxi, Changzhou, Nantong, Zhenjiang, Yangzhou, Xuzhou, Taizhou, Yancheng, Lianyungang and Suqian. In Xuzhou city, this result and the ranking of $F_{2}$ are relatively backward. Therefore, the development of city innovation ability needs to improve the regional economy and technological input.The cause of Xuzhou city innovation ability weak mainly has the following points:

First, during the development of the city, the local government pays more attention to the construction of the hard power, while pays less attention to the city soft power construction.

Second, Xuzhou innovation environment construction relative lag.

Third, Xuzhou economic development level is backward, scientific research investment is little.

\subsection{The Suggestion on the Development of Xuzhou City Innovation Ability}

To begin with, the local government should on the one hand adjust the industrial structure according to their resource advantage. Improve the level of economic development, on the other hand Increase research investment.

In addition, the local government should pay more attention to create a good environment for innovation. Government should not only increase investment in the construction of basic municipal facilities, but also enhance cultural innovation ability. Cultural innovation belongs to the inner innovation of the city. It is more important to build a humane environment for the growth of innovative talents.

What's more, the local government should support for high-tech enterprise development, and strengthen cooperation with the surrounding area, especially the research and cooperation of hi tech, which So as to promote the development of industry across the region.

\section{Acknowledgements}

This study was financially supported by Xuzhou Science \&Technology Soft Science Plan Project (No.KC14RH130) 


\section{References}

[1]CHARLES LANDRY. The creative city: a toolkit for urbaninnovators. Earthscan Publications Ltd, 2000 .

[2] EIS. Comparative Analysis Innovation Performance. UNU-MERIT, 2008.

[3]Xiaozhan Wang. The research on the evaluation index system of livable rural areas inChina-by the case of rural areas in Henan Province. Agriculture and Agricultural Science Procedia 1 (2010) 456-461

[4]Wei Jiang, Liu Yi, Hu Sheng rong. Estimation of Innovative City Based on Principle Analysis Method. Journal of Hunan University (Social Sciences),2009,53-58

[5]Li Lin, Han Baolong. Evaluation Index System of the Competitiveness of Innovative Cities and its Empirical Application. Economic Geography.2011,224-229 